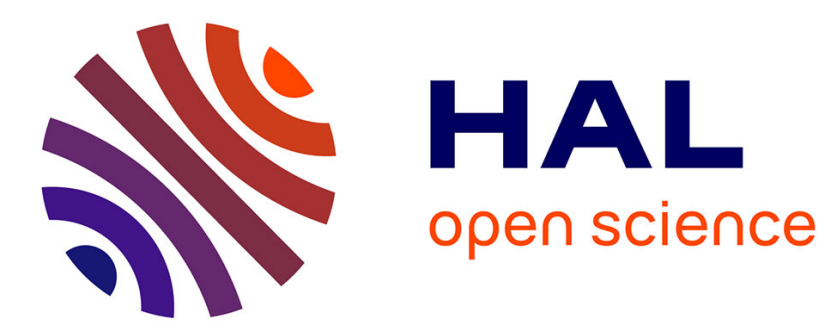

\title{
High Frequency Mn-Zn Power Ferrites
}

R. Lebourgeois, J.-P. Ganne, B. Lloret

\section{- To cite this version:}

R. Lebourgeois, J.-P. Ganne, B. Lloret. High Frequency Mn-Zn Power Ferrites. Journal de Physique IV Proceedings, 1997, 07 (C1), pp.C1-105-C1-108. 10.1051/jp4:1997131 . jpa-00255077

\section{HAL Id: jpa-00255077 https://hal.science/jpa-00255077}

Submitted on 1 Jan 1997

HAL is a multi-disciplinary open access archive for the deposit and dissemination of scientific research documents, whether they are published or not. The documents may come from teaching and research institutions in France or abroad, or from public or private research centers.
L'archive ouverte pluridisciplinaire HAL, est destinée au dépôt et à la diffusion de documents scientifiques de niveau recherche, publiés ou non, émanant des établissements d'enseignement et de recherche français ou étrangers, des laboratoires publics ou privés. 


\title{
High Frequency Mn-Zn Power Ferrites
}

\author{
R. Lebourgeois, J.-P. Ganne and B. Lloret* \\ Thomson-CSF/LCR, Domaine de Corbeville, 91404 Orsay cedex, France \\ * Thomson Passive Components, 74 route de Savigny, 21200 Beaune, France
}

\begin{abstract}
Relationships between chemical composition, microstructure and core losses of $\mathrm{Mn}-\mathrm{Zn}$ power ferrites are discussed. We report in this paper the influence on core losses of silica-calcia additions and Ti-substitutions for optimising a power ferrite from $25 \mathrm{kHz}$ up to $2 \mathrm{MHz}$. Our results are well explained using core losses description including the domain walls resonance-relaxation loss contribution depicted in previous papers and confirm that it is essential to take this contribution into account when optimising low losses ferrites in specific conditions of temperature, frequency and induction, especially in a high frequency range.
\end{abstract}

\section{INTRODUCTION}

The new generation of power converters requires higher operating frequencies to improve efficiency and compactness. Consequently, new active and passive components are needed. Among the passive components, the largest are the inductive ones such as transformers or inductances. In the middle and high frequency regions, magnetic cores of transformers are made with ferrites because these oxides exhibit high resistivities in spite of their low saturation magnetization compared with metallic materials (iron or silicon-iron). In SMPS (Switching Mode Power Supplies) applications, the operating frequency starts from $25 \mathrm{kHz}$ to go up to $2 \mathrm{MHz}$ while the operating induction decreases from $200 \mathrm{mT}$ to $50 \mathrm{mT}$ with working temperatures around $100^{\circ} \mathrm{C}$. Accordingly, power ferrites characteristics have to be determined considering the physical mechanisms which are involved in core losses. The aim of this paper is to discuss the relationships between the chemical composition, the microstructure and the parameters influencing core losses of a power ferrite such as the saturation magnetization $\mathrm{M}_{\mathrm{S}}$ and the total magnetic anisotropy.

\section{GENERAL CONSIDERATIONS}

Losses in magnetic materials have two main contributions: one is due to hysteresis and originates from the non-reversibility of the magnetization process, the other is dynamic and should be studied at a more macroscopic scale. For time harmonic fields, losses in magnetic materials can be depicted by a difference in phase between the external applied magnetic field and the resulting magnetization. Whatever its physical origin, this time lag is closely related to magnetization mechanisms which occur in the material. These mechanisms are the domain walls displacements and the spin rotations. Their relative importance depends on basic magnetic parameters such as the magnetocrystalline and the magnetoelastic anisotropies and the magnetic structure of the Weiss domains. For soft ferrites, the main contributions to core losses are:

- hysteresis loss mainly due to the non-reversing domains walls displacements. This contribution exists in all magnetic materials. For dynamic applications, hysteresis loss could be estimated as the area of the quasi-static hysteresis loop times frequency. Hysteresis loss can be reduced by decreasing the coecitive field. This can be achieved by increasing the saturation magnetization $\mathrm{M}_{\mathrm{S}}$, decreasing the internal stress, the magnetostriction and the magnetocrystalline anisotropy. For a polycrystalline ferrite, the porosity and mostly the intra-granular porosity must be kept as low as possible [1], [2].

- eddy current loss due to electronic movements to cancel the applied magnetic field. This kind of loss is a part of the dynamic contribution: it is magnified in metallic magnetic materials where the electrical conductivity is high and is often negligible for most ferrites. For all magnetic materials, eddy current loss can be reduced by increasing the dynamic resistivity. Moreover, eddy current loss depends on the structure of the Weiss domains, so for polycrystalline ferrites such as $\mathrm{Mn}-\mathrm{Zn}$ power ferrites, eddy current loss is microstructure dependent [3].

- resonance-relaxation loss due to either the reversible high frequency displacement of the domain walls or to the magnetization rotation inside a domain. It is another important part of the dynamic contribution which could dominate all other contributions if user does not take care. A practical way for choosing a ferrite is to consider the complex permeability 
spectrum for determining the frequency range in which losses occur (cf. figure 2). We have shown in previous works $([4],[5])$ that a relevant parameter to account for the efficiency of a (power) ferrite is the $\mu_{S} \cdot f_{\Gamma}$ product: the higher this product, the lowest the resonance-relaxation loss (cf. figures $1 \mathrm{a}$ and $1 \mathrm{~b}$ ). This is always verified on condition that the ferrite quality is good, that is to say that the chemical composition and the grain size are homogeneous.

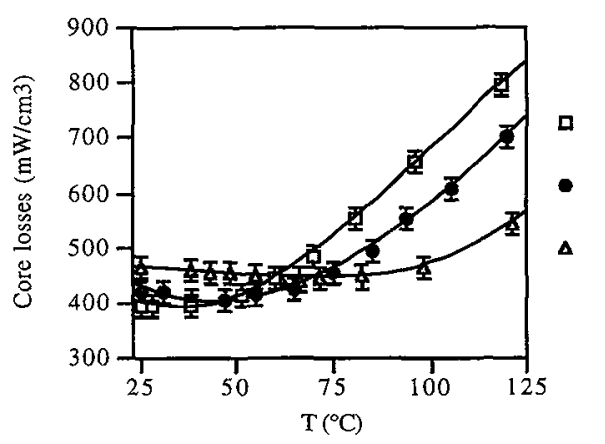

Figure la: Core losses at $1 \mathrm{MHz}$ and $50 \mathrm{mT}$ versus temperature of a high frequency $\mathrm{Mn}-\mathrm{Zn}$ power ferrite fired at $1200^{\circ} \mathrm{C}$ under various oxidation conditions $\left(\mathrm{O}_{2}=10,20\right.$ and $\left.30 \%\right)$

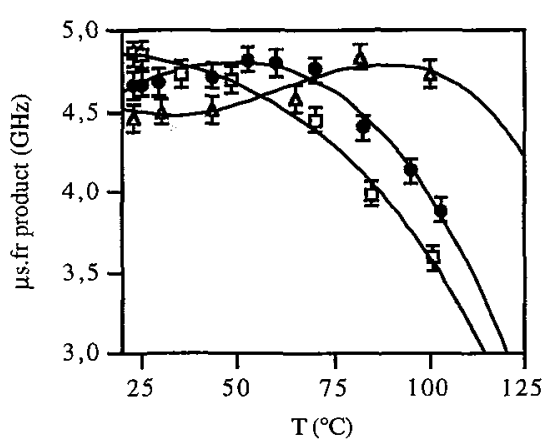

Figure $1 \mathrm{~b}: \mu_{\mathrm{S}} \cdot \mathrm{f}_{\mathrm{r}}$ product versus temperature of a high frequency $\mathrm{Mn}$ - Zn power ferrite fired at $1200^{\circ} \mathrm{C}$ under various oxidation conditions $\left(\mathrm{O}_{2}=10,20\right.$ and $\left.30 \%\right)$

\section{CHOOSING OF A POWER FERRITE: RELEVANT PARAMETERS}

Considering the permeability spectrum on figure 2 , it is clear that when approching $1 \mathrm{MHz}$, the resonance-relaxation loss will contribute to core losses. Below this frequency, the main contribution to core losses will be hysteresis loss and eddy current loss if the material exhibits a low resistivity.

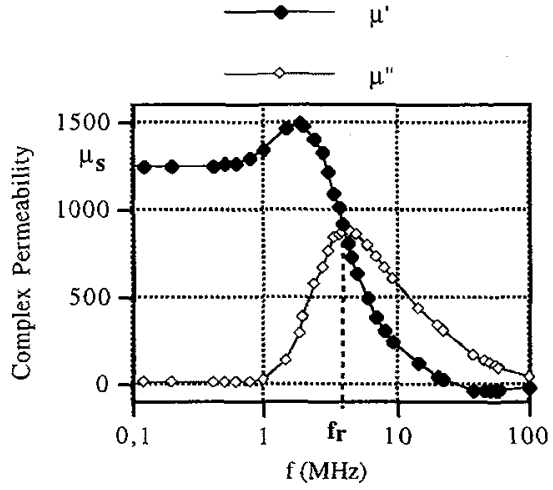

Figure 2: Complex permeability $\mu=\mu^{\prime}-j \mu^{\prime \prime}$ versus frequency of a high frequency $\mathrm{Mn}-\mathrm{Zn}$ power ferrite

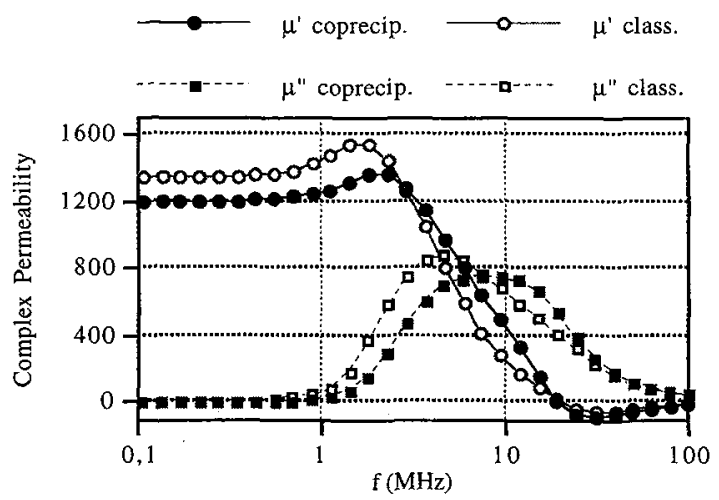

Figure 3: Comparison between complex permeability versus frequency of a classical and a coprecipitated $\mathrm{Mn}-\mathrm{Zn}$ power ferrite for high frequency applications

Although it is microstructure dependent, the $\mu_{\mathrm{s}} . \mathrm{f}_{\mathrm{r}}$ parameter may be considered as an intrinsic limit for a magnetic material. Experimental values of about $5 \mathrm{GHz}$ have been observed for high frequency $\mathrm{Mn}-\mathrm{Zn}_{\mathbf{n}}$ power ferrites [4],[5]. It is mainly connected to the saturation magnetization and to the magnetic structure. Some authors have tried to determine theoretically this parameter for polycrystalline ferrites according to the magnetization mechanisms involved $[6],[7],[8]$. Their models lead to the following relations:

$$
\begin{array}{lll}
\left(\mu_{\mathrm{s}}-1\right) \cdot \mathrm{f}_{\mathrm{r}}=\frac{12}{\beta \mathrm{D}} \cdot \mathrm{M}_{\mathrm{s}}^{2} & \text { in the case of domain wall motion } & \text { [6] , [7] } \\
\left(\mu_{\mathrm{s}}-1\right) \cdot \mathrm{f}_{\mathrm{r}}=\frac{\gamma}{3 \pi} \mathrm{M}_{\mathrm{S}} & \text { in the case of spin rotations } & \text { [8] }
\end{array}
$$

where $\beta$ is the damping coefficient, $M_{S}$ is the saturation magnetization, $D$ is the average grain diameter and $\gamma$ is the gyromagnetic ratio. From these relations, it appears that a power ferrite, more generally any ferrite, should have a high saturation magnetization and a fine microstructure. When the grain size is small, the $\left(\mu_{\mathrm{S}}-1\right) \mathrm{f}_{\mathrm{r}}$ product corresponding to the domain wall displacement is high and the spin rotations contribution is magnified [9]. Therefore the $\left(\mu_{\mathrm{S}^{-}}-1\right) \mathrm{f}_{\mathrm{r}}$ product increases 
whatever the magnetization mechanism involved. Figure 3 shows the permeability spectra for two Mn-Zn power ferrites: one has been prepared using the conventional ceramic route (class.), the other by the coprecipitation technology (coprec.). The main difference between these two ferrites is the grain size: the conventional ferrite has an average grain size between 6-7 $\mu \mathrm{m}$ whereas the coprecipitated one exhibits a fine microstructure with a lot of very small grains (1-2 $\mu \mathrm{m})$. As a consequence, the coprecipitated ferrite has a lower static permeability and a higher resonance-relaxation frequency. Moreover, we observe a $30 \%$ reduction core losses at $1 \mathrm{MHz}$ and $50 \mathrm{mT}$. As respectively the saturation magnetization and the dynamic resistivity are the same for both samples (resp. $0.6 \mathrm{~T}$ and $2 \Omega \mathrm{m}$ ), we conclude that resonance-relaxation loss is much lower for the coprecipitated sample. Under $3 \mathrm{MHz}$, the real part of the permeability is lower for the coprecipitated sample, after the contrary is observed. From $800 \mathrm{kHz}$, the coprecipitated sample exhibits lower losses compared with the conventional one.

The complex permeability of a conventional high frequency power ferrite has been measured under special biasing conditions (cf. figure 5): parallel biasing conditions where the static biasing field $\mathbf{H}$ is parallel to the alternative measurement field $\mathbf{h}$ (cf. fig. 4b) and perpendicular biasing conditions where the static biasing field $\mathbf{H}$ is perpendicular to the alternative measurement field $\mathbf{h}$ (cf. fig. $4 \mathrm{a})$. The $\left(\mu_{\mathrm{s}}-1\right) \mathrm{f}_{\mathrm{r}}$ product remains practically constant when the applied static biasing field is parallel to the alternative measurement field whereas it increases when the static biasing field is perpendicular. This could be explained considering that perpendicular biasing magnify the spins rotation contribution whereas parallel biasing magnify the domain wall contribution as it has already been observed for other samples [9]. As a consequence, the same sample may have different dynamic behavior according to the biasing direction (cf. figure 5): $\left(\mu_{\mathrm{s}}-1\right) \cdot \mathrm{f}_{\mathrm{r}}=5 \mathrm{GHz}$ in the parallel configuration when $\left(\mu_{\mathrm{S}^{-}}\right.$ 1). $\mathrm{f}_{\mathrm{r}}=10 \mathrm{GHz}$ in the perpendicular configuration. Then, a $\mathrm{Mn}-\mathrm{Zn}$ power ferrite presents better dynamic properties when the magnetization mechanisms involved are mainly spins rotation.

Figure 4 : Permeability measurements under DC magnetic bias $\mathbf{H}$. (a) : $\mathbf{H}$ is perpendicular to the base plane of the toroid sample and to the measuring field $h$

(b) : $\mathbf{H}$ is in the base plane of the toroid sample, parallel to the measuring field $\mathbf{h}$

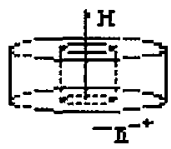

(a)

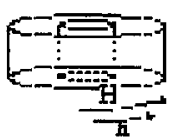

(b)

The total magnetic anisotropy of a ferrite which is the sum of the magnetocrystalline and the magnetoelastic anisotropies should be optimised according to the operating frequency range for preventing resonance-relaxation loss. Some authors have shown that Ti-substitution is a good way for both adjusting the magnetocrystalline anisotropy and increasing the dynamic resistivity of $\mathrm{Mn}-\mathrm{Zn}$ [10]. However, this is not sufficient when operating at high frequency and some additives such as $\mathrm{CaO}$ to increase the resistivity and $\mathrm{SiO}_{2}$ to increase the density are necessary [11]. Table 1 summarizes the effects of microstructure, additions and substitutions on the different contributions to core losses. More details are given in the next paragraph.

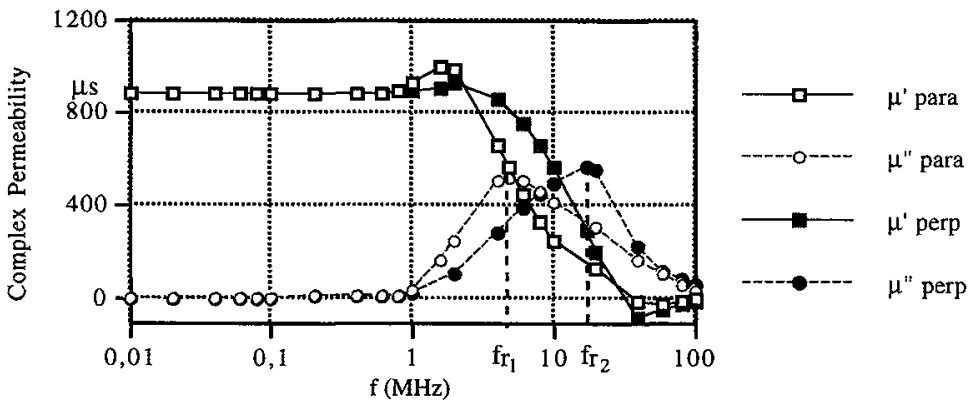

Figure 5: Complex permeability $\mu=\mu^{\prime}-\mathrm{j} \mu^{\prime \prime}$ versus frequency for a high frequency $\mathrm{Mn}-\mathrm{Zn}$ power ferrite under special biasing conditions (perp = perpendicular biasing and para $=$ parallel biasing)

\begin{tabular}{|c|c|c|c|}
\hline & Hysteresis loss & Eddy current loss & Relaxation loss \\
\hline small grain size & high & low & low \\
\hline$\left(\mathrm{CaO}_{\mathrm{SiO}}\right)$ additions & high & low & low \\
\hline Ti-substitutions & low & low & high or low \\
\hline
\end{tabular}

Table 1: Relative effects of microstructure, additions and substitutions on the contributions to losses of a Mn- $\mathrm{Zn}$ power ferrite

\section{CHEMICAL COMPOSITION, RAW MATERIALS AND CERAMIC PROCESS}

The chemical composition and the microstructure of a power ferrite have to be chosen according to the operating frequency range and induction level. In all cases, the ferrous content $\mathrm{Fe}^{2+}$ is essential for obtaining a high saturation magnetization but it decreases the electric resistivity by magnifying the hopping mechanism between $\mathrm{Fe}^{2+}$ and $\mathrm{Fe}^{3+}$. The ways of increasing the electrical resistivity of $\mathrm{Mn}-\mathrm{Zn}$ power ferrites are: 
- $\mathrm{Ti}^{4+}$ substitution because $\mathrm{Ti}^{4+}$ acts as an electrostatic trap by pinning the electrons at $\mathrm{Fe}^{2+}$ sites. Its presence induces $\mathrm{Fe}^{2+}$ cations for maintaining the electronic balance and thus allows the minimization of the anisotropy constant $\mathrm{K}_{1}$ versus temperature. Like this, the minimum of core losses versus temperature can be adjusted. As $\mathrm{Ti}^{4+}$ must take place in the solid solution of the spinel phase, $\mathrm{TiO}_{2}$ has to be introduced before the first ball-milling (see figure 5).

$\mathrm{CaO}$ addition because $\mathrm{Ca}$ segregates at the grain boundary which leads to a highly resistive grain boundary [12]. Moreover, $\mathrm{Ca}$ acts as a grain growth inhibitor which increases the resistivity by maximising the grain boundary surface and overcomes the formation of a duplex microstructure consisting of abnormally large grains embedded in a fine grain matrix. We have shown in previous works ([5], [11]) that such a microstructure is responsible for relaxation loss due to the displacements of the very large domain walls at low frequency.

- $\mathrm{SiO}_{2}$ addition because silica is acting as a flux: it improves the density and may increase the average grain size if firing conditions are not optimised [11]. The silica content must be carefully controlled because above 0.02 wt $\%$, discontinuous grain growth takes place and core losses increase whereas the density is high [11]).

Thus, for synthetizing a power ferrite with high performances using the conventional ceramique route, the impurities content must be known precisely. Moreover, the powder reactivity before firing has to be adjusted (specific area and oxidation state).

In the middle frequency range $(32 \mathrm{kHz}-100 \mathrm{kHz})$, the grain size of power ferrites must be homogeneous and the optimum average grain size should be between 10 and $20 \mu \mathrm{m}$. If the grain size is lower, the magnetocrystalline anisotropy should be lowered to adjust the resonance-relaxation frequency so saturation magnetization will decrease. In the high frequency range ( $300 \mathrm{kHz}-2 \mathrm{MHz}$ ), the grain size of power ferrites must still be homogeneous but the optimum grain size should be between 5 and $10 \mu \mathrm{m}$. So firing conditions must be determined for each power ferrite according to the frequency range: for middle frequency, firing temperature should be high $\left(1300\right.$ to $\left.1350^{\circ} \mathrm{C}\right)$ and for high frequency, firing temperature should be lower $\left(1200\right.$ to $\left.1250^{\circ} \mathrm{C}\right)$ and firing time should be reduced.

Moreover, during the firing, the oxygen partial pressure $\mathrm{pO}_{2}$ should be controlled to fix the right $\mathrm{Fe}^{2+} / \mathrm{Fe}^{3+} \mathrm{ratio}$, particularly during cooling [13]. In previous works [4], we observed that complex permeability and core losses minimum versus temperature were dependent on the oxidation degree and that it was related to the influence of $\mathrm{Fe}^{2+}$ content upon the magnetocrystalline anisotropy.

Using these considerations, a new high frequency power ferrite has recently been developed (reference F6). This ferrite could be used up to $2 \mathrm{MHz}$ and presents the following characteristics :

\begin{tabular}{|c|c|c|c|c|c|}
\hline & & Core losses & $00^{\circ} \mathrm{C}\left(\mathrm{mW} / \mathrm{cm}^{3}\right)$ & & \\
\hline Static permeability & Density $\left(\mathrm{g} / \mathrm{cm}^{3}\right)$ & at $1 \mathrm{MHz}-50 \mathrm{mT}$ & at $2 \mathrm{MHz}-40 \mathrm{mT}$ & Grain size $(\mu \mathrm{m})$ & $\mu_{\mathrm{s}} \cdot f_{\mathrm{r}}$ product $(\mathrm{GHz})$ \\
\hline 1000 & 4.7 & 470 & 1200 & $6 \pm 0.5$ & 5.6 \\
\hline
\end{tabular}

\section{CONCLUSIONS}

The optimisation of middle and high frequency $\mathrm{MnZn}$ power ferrites can be achieved using controlled additions and substitutions. $\mathrm{CaO}$ additions are useful for lowering the ac-conductivity and allows the average grain size minimization. SiO 2 additions improve the ceramic density without damaging the electromagnetic properties up to a $0.02 \mathrm{wt} \%$. $\mathrm{TiO}_{2}$ substitutions allow the adjustment of the total magnetic anisotropy. Understanding these influences has enabled to develop a new high frequency material having low losses between 0.5 and $2 \mathrm{MHz}$.

\section{References}

[1] L. Néel, "Base d'une nouvelle théorie générale du champ coercitif", Ann. Univ. Grenoble 22, p 299-343, 1946

[2] L. Néel, "Nouvelle théorie du champ coercitif", Physica 15, p 225-234, 1949

[3] G. Bertotti, "General properties of power losses in soft ferromagnetic materials", IEEE Trans. Mag., Vol. 24, N¹, 1988

[4] R. Lebourgeois, C. Deljurie, J.P. Ganne, P. Perriat, B. Lloret, J.L. Rolland, "New MnZn low-loss power ferrite for frequencies up to $1 \mathrm{MHz}$ influence of grain size and oxidization rate on electromagnetic properties", Proc. of the ICF 6, $p$ 1169-1172, 1992

[5] R. Lebourgeois, P. Perriat, M. Labeyrie, "High and low level frequency losses in NiZn and MnZn spinel ferrites", Proc. of the ICF 6, p 1159-1164, 1992

[6] A. Globus, Thesis, Paris, 1963

[7] M. Guyot and V. Cagan, "Temperature dependence of the domain wall mobility in YIG, deduced from the frequency spectra of the initial susceptibility of polycrystals", JMMM 27, pp 202-208, 1982

[8] J.L. Snoek, "Dispersion and absorption in magnetic ferrites at frequencies above one Mc/s", Physica 14, p 202-217, 1948

[9] R. Lebourgeois, C. Le Fur, M. Labeyrie, M. Paté, J-P. Ganne, "Permeability mechanisms in high frequency polycrystalline ferrites", SMM12, Krakow, to be published, 1995

[10] T.G.W. Stijntjes, J. Klerk, "Magnetic properties and conductivity of Ti-substituted Mn-Zn ferrites", Proc. of the international conference on ferrites (1970), p191

[11] R. Lebourgeois, J.P. Ganne, S. Pignard, P. Garrin and B. Lloret, "Effect of additions on electromagnetic properties of high frequency Mn-Zn ferrites", Proc. Electroceramics IV, Vol II, p 1137-1142, Aachen, 1994

[12] M. Paulus, C. Guillaud, "Technical magnetization. Structure granulaire et propriétés des ferrites" J. Phys. Soc. Jpn, 17, Sup. B1, 1962

[13] R. Morineau and M. Paulus, "Chart of $\mathrm{pO} 2$ versus temperature and oxidation degree for $\mathrm{Mn}$ - $\mathrm{Zn}$ ferrites in the composition range: $50<\mathrm{Fe}_{2} \mathrm{O}_{3}<54 ; 20<\mathrm{MnO}<35 ; 11<\mathrm{ZnO}<30$ (mole\%)", IEEE Trans.Mag.,Mag.11, p 1312-1314,1975 